\title{
Walter Benjamin's First Philosophy: Towards a Constellational Definition of Experience
}

https://doi.org/10.1515/opphil-2020-0006

Received September 19, 2019; accepted February 03, 2020

\begin{abstract}
This essay argues for the philosophical standing of Walter Benjamin's early work and posits a deeper continuity between this early work as a philosopher and the subsequent development of his work as a writer. When these fragments are read in proper relation to each other, they reveal for the first time many of the key innovations of Benjamin as a philosopher, as well as his points of influence on Horkheimer and Adorno. His early 'Program' critiques the Enlightenment conception of experience as a means for gaining empirical knowledge, and announces the need for a new concept of experience. Benjamin follows through on this program with a method of philosophical enquiry that is by turns fragmentary and constellational, developing a series of provisional notions of experience, which form a constellation with one another: perception, mimesis, language as a medium of experience, observation and memory.
\end{abstract}

Keywords: Experience; Perception; Surrealism; Memory; Critical Theory; German Romanticism; Proust; Walter Benjamin

\section{Introduction}

Walter Benjamin wrote on a great variety of subjects throughout his career, intertwining matters of aesthetic, cultural, political, technological and historical interest. It is neither necessary nor possible to find a single unifying thread, nor a method that underlies his great variety of writings. But it is easy to lose sight of the fact that Benjamin started his career as a philosopher, and that the problems and vocabulary of this period stayed with him throughout the rich variety of his writings. ${ }^{1}$ This essay will argue that in Benjamin's early 'Program for the Coming Philosophy', he develops not only a set of questions but also a set of conceptual innovations that set the path for an original 'first' philosophy. This original philosophy can be summarized as a definition of experience that is both mobile and foundational to his thinking. However, grasping this definition will require a short consideration of the method of definition that underlies Benjamin's writing. As much as Benjamin's thinking may be considered to be anti-systematic, it

1 One of the most exhaustive studies of Benjamin's early work is Tagliacozzo, Experience and Infinite Task: Knowledge, Language, and Messianism in the Philosophy of Walter Benjamin. The book emphasizes the ways in which the early Benjamin was influenced by the neo-Kantian school and early phenomenology, providing a deep genetic analysis of key concepts. There is a fundamental contrast in our approaches: Tagliacozzo's work reads the early Benjamin essentially as an epistemologist. She relates the themes of experience and language to the problem of knowledge, and emphasizes the early Benjamin's continuity with neo-Kantian epistemology. My own work, by contrast, highlights Benjamin's critique of those approaches that equate philosophy with a disciplining of knowledge. I argue that Benjamin formulates key notions such as experience and truth in such a way as to break them out of the ordinary context of epistemology: experience is not merely an object of knowledge, and truth is not a property of acts of knowing. My approach also draws a sharper contrast between Benjamin and the neo-Kantian school from which he sometimes draws terms. However, in my discussion of Benjamin's philosophical method that follows, I do acknowledge certain key agreements with Tagliacozzo, such as her treatment notion of definition through constellation and thought image. See note 7.

*Corresponding author: Nathan Ross, Adelphi University, Garden City, United States of America; E-mail: NRoss@adelphi.edu 
nevertheless possesses a "classically strict power of definition" 2 that allows us to find both philosophical discipline and continuity in his work.

From roughly 1916 to 1924, Benjamin wrote a number of texts that circle around the discussion of interrelated themes: truth, knowledge, metaphysics, the mind-body duality, perception and, especially, experience. There are two related voices in which Benjamin writes these texts: one voice is programmatic, while the other is fragmentary. The programmatic voice is reaching towards a new set of questions, without promising an answer, fearlessly seeking to uncover open space that has been ignored, without limiting itself only to questions that it can resolve. The fragmentary voice, on the other hand, provides theses that could be seen as answers to the questions posed by the programmatic texts. But these theses are fragmentary, in that they seem too direct, too deprived of any context or explanation: the theses mostly present a juxtaposition of concepts that have to be thought together in a constellational manner to be understood.

Even if Benjamin does not manage to solve the problems that he poses in his early writings, the questions themselves deserve to be heard and studied. These questions center around the concept of experience. What does it mean to have an experience? What are the different modes or forms of experience, and how do they fit together into a continuum? Most importantly, how is experience different from knowledge as a goal or pursuit? What if truth is not a property of acts of knowing, but of experience? In the first section of this paper, I will seek to emphasize the originality of the questions that Benjamin poses in his early writings, even when he is not yet able to come to a solution. These questions clear a certain space for thinking in a new way about experience. The second section will then explore the series of fragmentary answers that work together to provide a kind of constellational answer to the questions noted above. His early texts call for a new notion of experience, and throughout various phases of his career, right up the late Arcades Project, he provides such a notion fragmentarily through a set of evolving concepts: perception, mimesis, language and memory.

The theses that Benjamin presents-mostly in different writings from the same period-seem meant to respond to these questions, albeit in a startlingly cryptic manner. Here are a few of the major theses:

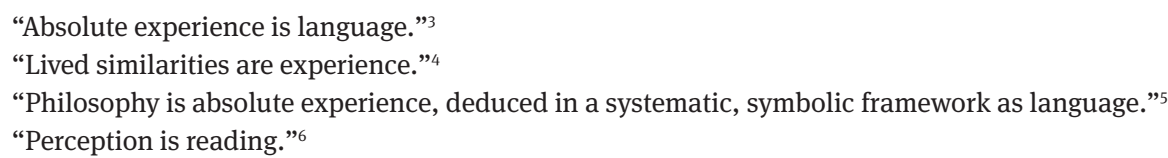

Each of these theses offers a juxtaposition between two or more concepts, with a promise of defining one through the other: philosophy is defined as absolute experience; absolute experience is defined as language; and both experience and language are defined through a mimetic element, the repetition of a lived experience, the recognition of patterns. But the answer withdraws from view, because the definans is just as under-determined as the definatum. Benjamin defines one term through another seemingly more familiar one, but on closer examination, his use of even familiar concepts entails a good degree of further thought, since he understands language and memory in very specific terms. But the point is not to establish an analytically exhaustive definition, but a constellation in thinking. Benjamin (and after him Adorno) will

2 Adorno, 'Einleitung zu Benjamins Schriften,' 571.

3 'On Perception', SW 1, 96/GS VI, 38. Citations generally follow: Walter Benjamin Selected Works, ed. Eiland and Jennings. And in German, Walter Benjamin, Gesammelte Schriften. The texts cited from GS VI are fragments, which make up the bulk of the primary texts for this study.

4 'On Experience', GS VI, 89. Translation altered from Eiland and Jennings, see below. See SW 2.2, 553.

5 'On Perception', SW 1, 96/GS VI, 37.

6 'Perception is reading', SW 1, 92/GS VI, 32. 
seek to define terms not through establishing a univocal use of the term, but by establishing a constellation. ${ }^{7}$ It is precisely by grouping Benjamin's negative and incomplete answers around each other in such a way that no one thought prevails, but what is incomplete in one finds its resonance in another attempt, that we get the sense of a living whole of thought. ${ }^{8}$

\section{The Program of a 'Mobile and Contradictory Whole'}

Benjamin's text 'On the Program of the Coming Philosophy' is perhaps most indicative of his tendency to pose original questions to which he does not yet have a solution, but which orient him towards new philosophical discoveries. Even if Benjamin does not follow through on all of the problems he poses for philosophy in this text, it is crucial to understanding the context of many of his later fragments, the ways in which they relate to a common set of problems. ${ }^{9}$ Even if it does not give the definitions that it posits as crucial problems for philosophy, it does at least provide certain crucial negations that pave the way for some of Benjamin's most original constructions.

Modern philosophy stands in an ambivalent relation to the concept of experience: it requires experience as the basis of epistemically safe cognition, yet it also reduces experience to something less than what it actually is, a material rather than a medium. In order to grasp experience in its full potential we must recognize the ways in which modern philosophy has biased us towards thinking in terms of one aspect of experience, while ignoring or stifling others. Benjamin's develops this point primarily through a reading of Kant, but it is important to understand his claims about Kant in a broader context that transcends the history of philosophy: the ambivalent and limited way in which Kant treats the concept of experience is perhaps indicative for Benjamin of the larger way in which our modern, scientific practices of knowing operate, and thus indicative of a larger cultural trajectory that Benjamin would eventually come to describe as the loss of experience.

He makes a stark claim about the philosophy of the enlightenment, culminating in Kant: this philosophy depends on experience to provide the material or impetus for knowledge, but it does not ever pose the question of what it means to have an experience. It does not seek an exhaustive or deep knowledge of experience, but rather looks at experience in an instrumental, or what Benjamin calls a 'superficial' manner. He writes of the enlightenment's notion of experience: "As an experience of the world, it (experience) was reduced to the lowest order."10 The notion of experience undoubtedly plays a key role in Kant's critical project. Kant's Critique of Pure Reason uses experience as a safeguard to protect cognition against metaphysical dogmatism, and perhaps more importantly for Benjamin, the critical project in its entirety even provides a general typology indicating that there are different modes of experience (ethical, scientific, aesthetic). This latter point of classifying and distinguishing different forms of experience remains for Benjamin a defining

7 Tagliacozzo argues that Benjamin derived his notion of constellation in crucial respects from Max Weber's notion of 'ideal types' or historical essences. She uses the definition of capitalism in Weber and Benjamin as an example of the method of giving definition to a complexly interwoven set of historical features that nevertheless form a 'whole' or 'idea.' In her comparison, this makes theory formation dependent on the work of composition or Darstellung, a term that both Weber and Benjamin employ. She writes: "Ideas are eternal constellations and configurations of concepts, which gather, decompose, and analyze phenomena by reducing them to conceptual elements that are most precisely explicated at their extremes, in the paradoxes of historical reality, and that cannot be ironed down with universal concepts.” Tagliacozza, Experience and Infinite Task, 137.

8 The term constellation plays a central role in Benjamin's early philosophy and gets taken up explicitly by Adorno, who defines it as such: "By gathering concepts round the central one that is sought, they attempt to express what that concept aims at, not to circumscribe it to operative ends.” Adorno, Negative Dialectics, 165.

9 One of the deepest studies of Benjamin's Program in the secondary literature is by Howard Caygill. He sees the work as foundational for understanding Benjamin's philosophy of experience, but regards the program as a failure, which orients Benjamin towards nihilism. See Caygill, Walter Benjamin: The Colour of Experience, 3. "Benjamin's elaboration of a nonHegelian speculative experience (in the Program) provoked many false starts and unhelpful digressions and may in the end be judged a cautionary failure.” For more on the nihilism of this position, see Ibid. xii. See also Wolin, Walter Benjamin: An Aesthetics of Redemption, 31. Wolin here calls the Program 'short lived'. I propose reading the Program as posing questions to which Benjamin would return in different ways later, coming up with alternate, related answers.

10 'On the Program of the Coming Philosophy', SW 1, 101/GS II 1, 158. 
goal of the 'coming philosophy'. But he argues that "(Kant) undertook his work on the basis of experience reduced to a nadir (Nullpunkt), to a minimum of significance" in that he "presupposed an experience which had almost no intrinsic value and which could have attained its sad significance only through its certainty."11 Experience is significant for Kant because it grants us a basis of tangible certainty that we could not find in mere thinking or speculation. In positing this relation between experience and cognition, Kant does not consider the problem of experience in its own right, for example, by asking whether there are not aspects of experience that withdraw from cognition. By defining experience in this manner as a guard against empty thought, experience is robbed of its own marrow. It only becomes knowable as a means to certainty, but it has no intrinsic value. Benjamin's early philosophy will consistently distinguish between 'means' and 'medium', between the use of language as a tool and the richness of language as a medium of experience.

Benjamin posits an essentially temporal reason why the focus on knowledge limits the ability of Kantian philosophy to grasp the true nature of experience: knowledge is a result, a product that stands, while experience is transitory. He writes: "The problem faced by Kantian epistemology, as by all epistemology, has two sides, and Kant only managed to give a valid explanation of one of them. First, there was the question of the certainty of knowledge that is lasting, and second, there was the question of the integrity of experience that is ephemeral." ${ }^{12}$ There are aspects of experience that can be distilled as a product that stands, but the stream itself is not reducible to this product. Kant seeks after what Benjamin calls the Rechtfertigung of a mode of experiential understanding, which of course relies on what is 'fertig' - the validity and transferability of the finished, the product that stands up to flux and change. In focusing so exclusively on the side of experience that can become a product of certain knowledge, Benjamin notes another inherently philosophical question that falls away: the question of the continuity of what is ephemeral in experience. It is not so much the continuity of the I or the substantiality of the soul that Benjamin has in mind here. Rather, he is after the connection between different times, different ways, different densities of experience, the ways in which they exclude, but also impact each other. In Benjamin's subsequent philosophy, the theme of memory would be one way in which Benjamin explores this problem of the continuity of what is ephemeral, and Proust serves as the greatest exponent of this uncharted territory. What Benjamin demonstrates through Proust is that memory is not a form of knowledge, but rather a medium. Memory does not preserve an experience as something stable, but allows an experience to interpenetrate with another experience and become something different than what it is. The memory of youth is not the same thing for the old man as for the young one. It is not a question of an experience being distorted or preserved, but of coming into its own through translation into another medium.

Benjamin seeks to recover one of the deepest problems from Kant's philosophy: how is metaphysics possible? In Kant's understanding of his Critique of Pure Reason, the purpose of tracing the limits of knowledge is to provide us with a key to resolving the deepest, timeless questions of philosophy, the problem of metaphysical knowledge. Kant is not so much a philosopher of experience as a metaphysician who uses 'experience' as a safeguard against vacuous speculation. But Benjamin argues that behind Kant's back this leads not only to a simplification of the notion of experience into a purely scientific, cognizable form, but also to a neglect of the very metaphysical foundations of his own simplified notion of experience. In assuming that this reduced notion of experience can protect cognition against metaphysical speculation, Kant fails to question the metaphysical foundations of experience in general. Experience is not simply a safeguard against metaphysics, but itself a source of metaphysical models and questions. He writes that Kant's epistemology "contains within itself primitive elements of an unproductive metaphysics that excludes all others." ${ }^{13}$ This effort to immunize thought against metaphysics through the notion of cognitive experience does not return the subject to the world of experience, but separates experience from its whole breadth and depth of experience: "In epistemology, every metaphysical element is the germ of a disease that expresses itself in the separation of knowledge from the realm of experience in its full freedom and

11 Ibid.

12 Ibid.

13 Ibid., 159. 
depth." ${ }^{14}$ What is needed, for Benjamin, is a new inquiry into the metaphysical foundations of experience itself, an enquiry that does not assume one model of experience. But such an enquiry begins not so much through positing experience as an open-ended continuum, but rather with an account of the limits beyond which the critique has to travel.

Benjamin explores the metaphysical foundation of the enlightenment's concept of experience: "The notion, sublimated though it may be of an individual living ego which receives sensations by means of its senses and forms ideas on the basis of them plays a role of the greatest importance in Kant's epistemology."15 As accustomed as this picture has become for us, Benjamin calls it mythic: "This notion is however mythology, and so far as its truth content is concerned, it is the same as every other epistemological mythology." ${ }^{16}$ In Benjamin's view, the myth at the root of the enlightenment's concept of experience consists in positing the subject and object as existing independently and outside of any historical development. Whenever Benjamin speaks of 'mythology', he is not simply dismissing something as a false belief. Benjamin employs the notion of myth to indicate that the belief in the independence and relationality of subject and object is a way in which thinking makes a relation that is highly historical and culturally contingent into a mere fact that does not need to be posited by the subject. Benjamin compares this particular view of experience to those pre-animistic peoples, or those pathological cases, where a subject identifies its own activity with the object of cognition. "Cognizing man, the cognizing empirical consciousness, is a type of insane consciousness." ${ }^{17}$ In taking the posited result of experience as the real thing, rather than as a stopping point within a fluid continuum of forms, this standpoint results in fetish worship. "Experience however is the symbol of the context of knowledge and therefore belongs in a completely different order of things from knowledge itself." 18

Benjamin offers a striking metaphorical analogy in order to expose the true relationship between knowledge and experience: "If a painter sits in front of a landscape and 'copies' it, the landscape itself does not occur in the picture." ${ }^{\prime 19}$ In a similar manner, he says that the 'experience of cognition' depends on the natural concept of experience as its context and basis, but such an experience does not enter into it. The painting relates to the landscape as cognitive experience relates to experience itself. The problem is not whether the copy in some sense matches the original, but rather the way in which the copy becomes a fetish object. In short, Benjamin wants us to identify ourselves and the act of philosophy with absolute experience rather than with a specific, historically mediated model of cognitive experience. This might seem like a fruitless demand for theory to say the unsayable, to immerse itself in the effable. But it is important to note that in Benjamin's early thinking, it is merely the context of knowledge that is limited relative to the context of experience, and not language itself. Language is not reducible to cognition, and this means that it does not stand in the same relation to experience that Benjamin described with the painting analogy. Benjamin would not argue that language is somehow a limited medium in relation to the larger context of experience. Indeed, Benjamin proposes the formula that "(a)bsolute experience is language." ${ }^{20}$ Thanks to his essay on language, Benjamin is in possession of a way of thinking of language not merely as a means of communicating information, but as an absolute medium in which various layers of reality express themselves and come into fruitful contact with each other. Benjamin introduces this notion of absolute experience along with the following definition of philosophy: "Philosophy is absolute experience, deduced in a systematic, symbolic framework as language." ${ }^{21}$ In other words, philosophy is not fundamentally defined by epistemology, but rather by the task of translating experience into a symbolic context. Philosophy might consider itself 'queen of the sciences' to the extent that it arbitrates the status of knowledge claims made in other sciences, but in 'The Life of Students' Benjamin has another way of thinking of the centrality of

14 Ibid.

15 Ibid., 161.

16 Ibid.

17 Ibid.

18 Ibid., 36.

19 Ibid.

20 'On Perception', SW 1, 96/GS VI, 38.

21 Ibid., 37. 
philosophy within intellectual life: philosophy is the discipline of asking questions about why knowledge matters, the discipline that resists making all pursuit of truth into a result that can serve a purpose. What does it mean here to define philosophy as a matter of deducing absolute experience in language?

In his notion of absolute experience, the context of experience counts not as a material, which has to be measured analyzed and in some sense converted into cognition. Rather, such experience is the medium itself in which all meanings, especially all diversity of human meanings, come into contact. Experience is not essentially epistemic, although epistemology may need it, but it is essentially linguistic. What does it mean to assert that 'absolute experience is language'? In Benjamin's philosophy of language, human language is only a subcategory of language in general, words are only one form of language, a form that responds to the language of nature or the reticent language of images or music, by translating their language into words. Language is for Benjamin, at its most fundamental level, not a means of conveying thoughts, but a medium in which translation from one mode of expression to another takes place. Knowing in a scientific manner is one way of translating an experience into a different context, but experience is fundamentally this process of moving between different symbolic frameworks. Put another way, knowledge seeks to reify experience, but experience is fundamentally the living relationality between different symbolic orders. The painting is not the landscape, but the painter is a translator who seeks to translate the one into the other. What interests Benjamin is not to analyze the product, the painting, but rather the process in which one passes over into the other and becomes something other than itself. This act of translation is guided not so much by the problem of accuracy, since language is not merely a set of information that has to be preserved, but rather guided by the demands of bringing different densities, different layers of language, into contact in a fruitful way that increases their responsiveness to one another.

In developing this critique of the modern notion of experience, it might seem as if Benjamin is working towards something like a phenomenology of pre-reflective 'lived' experience. It is important to note, however, that Benjamin does not place reflection into an antithetical relation to experience: indeed, reflection, study and thinking are ways of deepening and unfolding experience throughout Benjamin's thinking. At this phase, it might be helpful not to read more into this text than what its title implies: it is a 'program' for future philosophizing. It makes demands, without necessarily being able to make good on all of these demands. I note each of these demands here, in the hopes that they relate fruitfully to other texts and themes in Benjamin's work: (six total)

(1) "to develop a higher notion of experience out of the typology of the Kantian system":22 What clues does Benjamin give us as to this 'higher concept of experience'? First, it must offer a typology of experience, in much the manner of Kant: a classification of the types of experience that are possible. But unlike Kant, it must activate the metaphysical foundation of experience in a manner that is fruitful. (He calls the Kantian metaphysics of experience 'fruitless': the subject/object relationship becomes veiled in the absolute impenetrability of the thing itself. A 'fruitful' metaphysics of experience would show the subject-object relationship in a manner such that the diversity and richness of experience would depend on the variety within this relationship. More on this fruitful metaphysics in point three.

(2) to differentiate the value of various forms of consciousness ${ }^{23}$; to trace the continuity of various forms of consciousness ${ }^{24}$

The 'Program' says that we must find the criterion for the difference in value (Wertunterschied) of various forms of consciousness. It does not say what this criterion is. But this much is clear: the value of experience has to be understood in terms of the overall possibility of further experience, not its relation to knowledge. He proposes that we look at various modes of experience not from the standpoint of knowledge, of epistemic validity, but from the standpoint of their intrinsic value within a continuum. To have experience means to have a sense of the value of various forms of consciousness in relation

22 'Program', SW 1, 101/GS II 1, 160.

23 Ibid., 162.

24 Ibid. 
to each other, the way in which one experience allows us to reflect on another. Following his notion of a continuum of modes of consciousness, we could propose critiquing each experience as a monad, in the sense that it latently contains each other monad, offering a different perspective and a varying degree of clarity. Throughout his work, Benjamin frequently takes on the variety and continuity of forms of consciousness in many ways: his writings on memory, on insanity, on color, on semblance, on intoxicating substances, on new artistic media that make new demands on our senses, to name just a few. In each of these instances, he considers the way in which one kind of experience distinguishes itself but relates back to another experience: the way in which insanity reflects back on sanity; the way in which memory fruitfully alters the remembered state; the way that one language can express another language; the way that new forms of aesthetic experience alter our understanding of more traditional ones. The key to understanding these writings is perhaps found in the formulation of this demand: to understand experience not in terms of the product that it generates, but in terms of its relation to other modes of consciousness. Although Benjamin does not name the meta-value under which these modes of experience are to be considered, it must be something immanent to experience, and it argues that philosophy must search for such a meta-value. Perhaps the closest that Benjamin comes in his early writings to providing such an immanent, experiential meta-value is his eulogy to sobreity as the supreme value of Romantic philosophy: sobriety is not the lack of intoxication, but the state of consciousness that allows one to ascend and descend the ladder of various state of consciousness in a reflective and communicative manner.

(3) "to find the sphere of total neutrality in relation to both subject and object"25

This is arguably the most specific, and yet most mysterious of the demands that he makes in this essay. It gives us a hint of the more fruitful metaphysics of experience that Benjamin seeks to counterpose to the 'fruitless metaphysics' underling the Kantian notion of experience. But Benjamin does not explain very well what he has in mind with a 'sphere of total neutrality in relation to both subject and object.' It is clear that Benjamin finds such a neutrality between subject and object sorely lacking in Kantian and neo-Kantian epistemologies. ${ }^{26}$ In these philosophies, we could argue that the concern for the structuring of experience by the subject leads to the emptying of the object: the object eventually gets thought as a mere material or incitement to experience, rather than a pole that has its own activity and influence. It was perhaps Schiller and the Jena Romantics who first charged Kant with creating a notion of experience in which intellect dominates sense, in which the active subject makes the object too passive. When the subject dominates the object in this manner, it leads philosophy to ignore the role of history in shaping consciousness, what Benjamin calls the 'historical blindness' of the enlightenment. And Benjamin's demand for a sphere of neutrality between subject and object leads his thinking in two crucial directions: first, it leads him to a staggeringly original account of post-Kantian Romantic epistemology as taking place within a medium of reflection. Benjamin argues in his dissertation that for the Romantics, we can only have knowledge of an object if we see the object as a subject that is capable of reflection and awareness of its own. The Romantics thus offer Benjamin a more 'fruitful' metaphysics of experience, in which the subject does not dominate the object. But secondly, this search for a sphere of neutrality leads Benjamin to a philosophical itinerary that pays special attention to the relative diversity and potency of objects of experience. He writes on subjects such as color, childhood, the experience of intoxicating substances, on artistic media that incite social change. To have an experience means to come into contact with an object that redefines the very nature of experience, because it does not fit any conceptual category or function. Where Benjamin uses the term 'sphere' here

25 Ibid., 163.

26 Tagliacozzo provides a plausible approach: "Benjamin seeks to establish the sphere of knowledge beyond the subject-object relation, overcoming the conception of an empirical consciousness that knows objects, distinguishing instead a non-synthetic relation of identity among concepts and ideas, in which truth ... is given as a nonintentional unity, an concepts gather like constellations around guiding ideas”. Tagliocozzo, Experience and Infinite Task: Knowledge and Messianism in the Philosophy of Walter Benjamin, 37. This reading emphasized that rather than using concepts to interpret reality, they are arranged according to a constellation in such a way as to allow phenomena to appear. 
to designate the greater context that includes subject and object in a neutral manner, his subsequent thinking uses a related term: medium or media.

(4) A reformulation of the notion of freedom in line with the new concept of experience ${ }^{27}$

Kant bases his notion of freedom, and hence the ideal of practical philosophy, on the negation of the empirical: to be free means to give oneself a law that is entirely 'rational' in the sense of lacking any empirical specificity. It thus seems dialectically cogent that a critique of Kant's notion of experience as metaphysically fruitless must also lead to reconceiving the metaphysical nature of freedom. If experience is not a stream of particulars that come before a universal faculty, but rather a continuum that generates form, then freedom cannot be grasped as the absence or negation of experience, but as a relation in and to experience. The most fruitful way to follow this goal into Benjamin's latter thought would be to investigate the relation to suffering and history that he establishes in texts such as the Arcades project and the 'Theses on the Philosophy of History.' Benjamin remains suspicious of the enlightenment view of history that involves the rational subject liberating itself from dependence on nature. Redemption involves remembrance, specifically, it involves the acknowledgment of pain and suffering.

(5) The formulation of a new relation between error and truth ${ }^{28}$

This is perhaps the most far reaching and revolutionary demand that Benjamin makes in his program: "Error must no longer be understood in terms of mistake, and truth must no longer be understood in terms of the right understanding." Kant's own revolution consists in a new approach to truth: while older philosophy had understood truth and error at least partially as a metaphysical problem, Kant changes it into a problem of transcendental logic. Truth is for Kant no longer a failure in the relation of the subject to the object, but a failure in the subject's application of its own understanding to the specific case, an incorrect understanding of how the general conditions of cognition apply to the subject's present experience. Benjamin notes that Kant struggles to reconcile his notion of truth to the third part of his system, in which it is a matter of judging things that cannot be determined according to the concepts of the understanding, such as life, history and art. Benjamin seems concerned with reconceiving the problematic of truth and error in terms of the metaphysical demand to establish the metaphysical neutrality of subject and object: truth is no longer a quality of knowledge, in the manner of the exact, mechanical and mathematic sciences, but a quality of true being, a quality of the relation between any being and the constellation of historical circumstances in which it finds itself. One way that Benjamin thinks this problem is: to what extent can an artwork be true? It can only be true in the experience of its relation to the becoming of art in general. But the aesthetic is only one way that Benjamin seeks to reconceive of truth and error. In more general terms he proposes thinking of truth as a quality of circumstances.

(6) to understand experience as a matter of the relation of knowledge to language ${ }^{29}$

Every experience can find its way into language, but not every experience is an act of knowing. Language is the medium of experience. As Benjamin notes, Kant had devoted virtually no attention to the relation between language and knowing: the categories of the understanding seem to be timeless, cognitive structures that filter and shape experience. But what if our way of thinking is shaped by language? What if the fundamental categories that shape our thought and experience come to us through the words that we have learned? Benjamin focuses a great deal on the linguistic nature of experience: not just the way in which we articulate things in words, but the way in which we experience things as meaningful only to the extent that we apprehend them as symbols. For Benjamin there is a very handy German word for this symbolic dimension of experience: Wahrnehmung-Perception. I am constantly seeing things to the extent that they present themselves as symbols within a continuum, and then I am

27 'Program', SW 1, 105/GS II 1, 165.

28 Ibid., 167.

29 Ibid., 168 
translating them into a different symbolic context. Benjamin is by no means the only philosopher of the early $20^{\text {th }}$ century who undertakes a linguistic turn in specifying the relation of knowledge to language. But Benjamin's linguistic turn is radical to the extent that he makes language into something much more profoundly metaphysical than words or grammar: the 'language of man' is for Benjamin merely a fallen part of a much larger totality, the language of things. Language becomes a fruitful extension of Benjamin's program because of the way that it represents a continuum: he would later call language the medium in which all entities mix and communicate their essences with each other. Experience is not for Benjamin fundamentally the relationship between the knowing subject and the known object, but rather the relationship between symbol and symbol, between the act of expression.

On the basis of this reding of the Program, it now becomes possible to revisit Caygill's critical reading of this work: he ultimately claims that Benjamin fails to follow through on the demands developed in this program in his subsequent philosophy, but that it remains influential because inclines him to a kind of philosophical nihilism throughout his thought..$^{30}$ This reading is worth examining here not only because it is one of the strongest efforts to read the Program as shaping Benjamin's philosophical trajectory, but also because it seems to confirm a general impression of Benjamin as a thinker who is unable to found any coherent philosophical theory. On the first point, of failure and false start, the next section will demonstrate the ways in which Benjamin's subsequent philosophizing unfolds commitments developed in this program: although his answers to the demands found in the Program do not remain settled or clear, because of his constellational practice of philosophy, they do contain a kind of fruitful coherence in building on one another. But for now it is most important to touch on the claim that the Program contains the seeds of a nihilistic approach to philosophy. ${ }^{31}$ It is not easy to dismiss the claim that Benjamin's philosophy contains nihilistic elements throughout his work, as many of Benjamin's most provocative works, such as 'The Destructive Character' and 'Poverty and Experience' examine the need to begin anew through a negation of foundational values of European modernity. ${ }^{32}$ But Caygill seems to construe Benjamin's nihilism as one that would negate even the ground on which it is standing, that is, a philosophy that avoids any defining values of its own philosophical discourse. ${ }^{33}$ It is true that the Program contains a series of quite radical negative moments: it challenges the enlightenment view of experience as only serving as a basis of knowledge and announces the need for a new conception of truth. But this negative moment in Benjamin's thought is only provisional and challenging. The text does not argue, for example, that philosophy must dispense with the notion that truth is a guiding value, but argues that this guiding value has to be redefined in a broader context. It does not argue, as Caygill seems to imply, that experience is simply a kind of unbounded and indefinite continuum into which we should throw ourselves, but rather that a new concept of experience will create new imperatives for thinking. It is true that the Program challenges certain values that might seem to have a kind of unquestioned validity in a certain kind of philosophical practice, namely that experience is only thinkable as a basis for empirical knowledge or that freedom is only possible through a kind of break with sensible experience. But in critiquing these values, he seeks to ground philosophy in broader and more integral values that continue to guide his own thinking.

30 On this last point, see especially Caygill, Walter Benjamin: The Colour of Experience, xii.

31 Caygill gives his most generous reading of such nihilism in the following, likening Benjamin to Nietzsche: “Benjamin's work may be read as an exploration of the ambiguities of nihilism, an attempt to establish a 'method called nihilism' which would offer both a diagnosis of the experience of a passively nihilistic culture as well as the possibility for an active nihilism emerging within it." Caygill, Walter Benjamin: The Colour of Experience, xii.

32 See Ponzi, Nietzsche's Nihilism in Walter Benjamin. Here Benjamin's thought is construed as a kind of dialogue with nihilism, in which nihilism represents an important element within his thinking.

33 For example, he writes that Benjamin's philosophy of experience "threatens the identity of philosophy with itself" (Caygill, Walter Benjamin: The Colour of Experience, xiii) and "negates any possibility of sense" (Ibid., 3). It seems to me that it is possible to counter this reading with one that emphasizes provisional sense and anticipatory meaning making. And in its starkest rendering, he writes that Benjamin's method of "active nihilism allows him to invade, evade and even ruin its philosophical host” (Ibid., xiii). These formulations indicate that for Caygill, Benjamin's nihilism is not merely a philosophical position, but ultimately non-philosophy. 


\section{Models of Experience: Perception, Mimesis, Language and Memory}

Up to this point, it might seem as if Benjamin's early philosophy tends to write checks that it cannot cash. His Program develops a whole series of demands that would characterize a deeper and more authentic notion of experience, but these demands do not yet have the character of a definition or analysis. Experience is to be the basis of a new notion of truth; it is to be based in the primacy of language over knowledge; it is to serve as the term of continuity and comparison between different acts or modes of consciousness; and it is to be an absolute medium, not a means to a higher end. In this section, I will look at the concepts through which Benjamin seeks to make good on these demands. Although Benjamin did not spend his subsequent career working in the milieu of neo-Kantian academic philosophy against which these demands were formulated, it is safe to say that the problem of redefining experience remains central to Benjamin's project up to the end and gives each phase of his writings a connection to the problematic of first philosophy. As Eiland and Jennings argue in their biography of Benjamin, "[t]hree concerns are always present in Benjamin's work-and each has its ground in the problematic of traditional philosophy. From first to last, he was concerned with the problem of experience, with historical remembrance, and with art as the privileged medium of both." ${ }^{34}$

The closest that Benjamin ever comes to offering a succinct summary of his notion of experience is in a short fragment Zur Erfahrung (fragment 59) from the year 1933. This text is remarkable because it contains in very dense form a series of conceptual innovations that are spread out over several decades of Benjamin's work, and thus reveals in a rare way the continuity of his thinking. The key sentence of this short text has been mistranslated in English. I add my emphasis to highlight the key sentence, which I have retranslated:

The type of man who has experiences is the exact opposite of the gambler.

Lived similarities are experience.

There is no greater error than to construe experience in the sense of living experience (Lebenserfahrung) that is at the basis of the natural sciences. What is decisive are not the causal connections that have been observed over time, but the similarities that have been lived.

Most people do not want to have experiences, because their convictions prevent them from doing so.

The identity of experience and observation is to be proven. See the notion of 'romantic observation' in my dissertation. Observation resting on immersion. ${ }^{35}$

Although this text from the later phase of Benjamin's life hardly satisfies all of the demands developed in his youthful Program, it condenses a series of crucial insights that are spread out over various periods of Benjamin's writing. The third sentence repeats the main negative insight of Benjamin's Program: that experience is not truly comprehended through the model of the empirical sciences. The text also emphasizes that Benjamin remains fundamentally committed to the model of Romantic object knowledge that he develops out of Schlegel and Novalis in his dissertation as an alternative to the Kantian model of cognition. It also notes that the capacity for experience can be lacking or lost as a result of certain pursuits or circumstances, a loss that Benjamin ascribes to a whole generation of his contemporaries in 'Experience and Barbarity'. But from the standpoint of the philosophical explanation of experience, the crucial sentence is the second one: 'Erfahrung sind gelebte Ähnlichkeiten. ${ }^{36} /$ 'Lived similarities are experience.' The true nature of experience is to live through similarities. By this point, the notion of similarity is of utmost importance to Benjamin's thinking, as he devoted an entire essay to 'The Doctrine of the Similar'. In this key sentence he posits as problematic the connection between life and similarity, and regards experience as the connection between the two. When life is looked at in the past tense, it is something 'lived,' a participle. Our orientation

34 Eiland and Jennings, Walter Benjamin: A Critical Life, 7.

35 'On Experience', GS VI, 89. See SW 2.2, 553. Translation altered from Eiland and Jennings, see below.

36 This sentence is translated: 'Experiences are lived similarities' in the Selected Works. This preserves the word order of the German, but incorrectly translates 'experience' as plural and makes it the subject of the verb. The plural sind and singular Erfahrung indicates that the subject is 'lived similarities.' In German the subject can be on either side of verb. This leads to a slight difference of emphasis: the text offers not so much a definition of experience, as an explanation of the doctrine of similarity through the notion of experience. Alternately, Beatrice Hansen also modifies the translation: "Experience consists of lived similarities.” Hanssen, 'Language and mimesis in Walter Benjamin's work' in The Cambridge Companion to Walter Benjamin, 69. 
to past life determines how we live in the present. Experience is fundamentally a relation of possession to those patterns that make up our own past. But this possession borders on dispossession, because these similarities are by no means given. Our thoughts, our attitude, or the cultural medium of the present can make us lose this fabric of lived similarity. Life can fundamentally fail to achieve its own rhythm of patterned self-relation. When it does this, there is no act of knowing that can make up for the disorientation that emerges within life. This is the closest that Benjamin comes to a rich definition of experience, and what it means for experience to be lost. But the terseness of this text conceals the richness of Benjamin's thinking on this point. In order to understand the sense of this key sentence, it will be necessary investigate the crucial role that 'lived similarity' plays in Benjamin's thinking, the variety of meanings that he gives to this term.

Benjamin's practice of philosophy is essentially both dialectical and constellational. His method is dialectical in that he analyses each term first by negating a cliché that surrounds it, thus depriving us of a certain crutch that we might use to simplify our understanding of a term. He presents us first with the insufficiency of a non-reflective understanding of language, experience, or memory. But his thinking advances beyond such a purely negative practice of dialectic by placing this dialectical moment in relation to a constellational one. His thinking is constellational in the sense after directing us away from a reductive definition, he offers a series of terms, each of which includes a determinate variety of meanings and resonances, but also a certain degree of enigma or unresolved ambiguity, and then he places each term in a definite intuitive configuration with another such term, so that each will answer to some of the indeterminacies of the latter. I argue that there are four distinct original terms that Benjamin employs as models of absolute experience: perception, mimesis, language and memory. In addition to these four terms, there is also one historical precedent that he explicates as crucial to his own notion of experience: the notion of observation in early German Romanticism. While each of these terms represents an effort to answer to the demands of a notion of absolute experience, it will be impossible to fully understand one without looking to the other. Perception is perhaps the most basic model of an absolute experience, but it is also the model that Benjamin abandons the earliest. By contrast, mimesis becomes a constant throughout his thinking and it absorbs some of the most significant meanings that he ascribes to perception. Memory is finally the term that allows Benjamin to think all of the terms, perception, mimesis, lived similarity, observation and language, in a manner such that each is purified and reflects the others.

\subsection{Perception (Wahrnehmung)}

One of the most important terms in Benjamin's early thought is perception-Wahrnehmung.

As Hegel argues in the Phenomenology, perception happens when there is more than mere sensation, when there is a recognition of a pattern within the sensuous, when I am able to see each thing as an embodiment of a pattern or relation. Benjamin seizes on this theme of perception in order to illustrate the fundamental identity between experience and language. Perception is not a taking in of information, but a taking of things as true (wahr). Perception only perceives what it can interpret, which leads to Benjamin's thesis that 'Perception is reading. ${ }^{37}$

Perception is fundamentally the act of recognizing similarities within the stream of experience. As I noted above, the recognition of patterns remains fundamental to Benjamin's notion of experience: "Lived similarities are experience." ${ }^{38}$ Perception means seeing or hearing things in a way that draws from lived similarity. If I do not know a language and hear it being spoken, it will just sound like a jumble of sounds. But if I know the language, then my knowledge of the language will manifest itself in my ability to recognize each new thing that is said as a new use of something I have already heard. Instead of hearing sounds, I hear words. This level of listening is what it means to perceive. The same is true not just of the language of words, but of every other mode of perception: If I am experienced with coffee, I see the crema of the espresso

37 SW 1, 92/GS VI, 32.

38 SW 2.2, 553/GS VI, 89. 
and recognize right away if it has been made with fresh beans, if the beans have been burnt, if the coffee was drawn too long. My experience with coffee, as well as my capacity for fresh experience, means that I see each event as a similarity, as a variation on a pattern. To have experience means having the capacity to perceive: to be open to what is new and developing, while at the same time making sense of it as a pattern.

Of course, 'having an experience' in the most emphatic sense means not so much recognizing each thing as an instance of something familiar, but far more the ability to notice something as new and distinctive. It is precisely by having words, by looking for the right words, that I am able to see what is new as more than a mere repetition of the same. At the heart of his occupation with the problem of perception, Benjamin invokes insanity or madness (Wahnsinn) as a special illustration of what it means to be perceptive. For Benjamin, the insane person is one who is able to perceive to a greater degree. "Madness is a form of perception that is alien to the community." ${ }^{39}$ He considers insanity as an 'other' mode of perception, one that is alien to the community, and yet he notes that great scientific and philosophical discoveries always seem to the community to have something of insanity about them. ${ }^{40}$ If we consider Benjamin's definition of perception as the recognition of things within a pattern, then what makes insanity into a fruitful instance of perception? There is something quite insane in the instance where one person recognizes a pattern where there seems only to be a random set of occurrences. The great scientific discoveries usually involve a reversal of paradigm, not the observation of new evidence, but a diametrically opposed way of making sense of the evidence that is given. Thus we could propose that the truth seeker is someone who looks for something legible where the community has only seen a mass of insignificant events. For Kant, what makes cognition reliable is the fact that we all have the same filters, the same fundamental ways of interpreting what happens to us in experience. Although we might have different experiences or sensations, we have the same ways of synthesizing them in intuition and understanding. But in Benjamin's thought experiment, the truth seeker is someone who perceives a new legible order that seems insane because it is not reducible to the ones shared by the community. It is the accusation of insanity leveled against the truth seeker, rather than the communicability of scientific results, that serves for Benjamin as a model of what it means to have an experience.

Even though Benjamin defines perception through the analogy to reading, he is careful to make a distinction between perception and the other, more familiar ways in which we might read, such as signs and symbols. In one of the densest and most difficult fragments from this period, 'Notes on the Question of Perception' he seeks to define the relationship between perception, signs and symbols. For Benjamin, we can only read a sign or symbol to the extent that we perceive it, but perception is fundamentally more than a reading of signs. When I read a sign, I see it as a sensuous configuration that points me towards a meaning (Bedeutung). But perception itself has only reference (Deutung), but no meaning (Bedeutung). The sign asks to be read as referring to something that is not there, while perception reads only what is there as a system of self-reference. In a Hegelian framework we might say that reading the sign is higher than perception, because it sublates the act of perception into a higher mental act. We could not read a sign without perceiving it (the shape of the letters, the color means it is a stop sign, etc.), but the meaning is more than the color or shape of the letters. But Benjamin focuses on something different than the sublation: the aspect of perception that remains distinctive. "Perception distinguishes itself from the sign in the following manner: it is not the configuration within the absolute surface, but rather the configured absolute surface." In all reading and perception, we are only relating to a surface. Normally, we might consider the 'surface' as a binary term that relates to something else: the depth, the supersensible, or whatever lies underneath. But Benjamin writes here of a reading that relates to an absolute surface, a surface that is infinite and is not defined by its relation to a depth. In reading a sign, I read this absolute surface in its relation to something that is not surface and can never be, the meaning. But in perception itself, there is nothing other than relations within the surface. We could call perception a self-structuring, free and infinite play of appearances with no purpose beyond the realm of appearances. In reading a sign, the perception points (deutet) to something that is not a perception, but in perception there is also a pure pointing, a way in which

39 SW 1, 92/GS VI, 32.

$40 \mathrm{SW}$ 1, 92/GS VI, 32.

41 GS VI, 32. 
one perception leads to another perception. In other words, perception is still an interpretive act according to Benjamin, even when it does not lead us beyond the surface. Benjamin's reflections on this problem terminate in a striking conclusion: "The interpretation (Deutung) of the configuration of the absolutely flat surface is what is called its key (Schlüssel). . . the problem of perception culminates in the problem of the pure key." ${ }^{42}$ What is the problem of the pure key? It is a key that does not open a door. It is still a key in that it refers to something, but this something is not behind the door of experience. The problem of perception is that it refers (deutet) but does not mean (bedeutet) anything.

With this account of perception as a 'pure key', Benjamin seems to come very close to describing an aesthetic experience, an experience that lingers on the surface, finds purpose in tracing infinite variety of patterns and does not seek an abstract meaning beyond the riddle of the infinite play of appearances. But it is important to distinguish Benjamin's thought experiment here from any account of aesthetic experience that focuses only on the negative side of the aesthetic, its negation or lack of cognitive significance. For Benjamin, the word 'perception' is richer than such negative notion of the aesthetic, because it is not an isolated domain of experience, but the heart of all true experience. And what is more, the word perception (Wahrnehmung) contains within it the notion that it is directed towards truth content.

Perception is Benjamin's first attempt to think a notion of experience that answers to the demands elucidated in his Program, but he runs into limitations in this concept that require him to develop another concept that answers these demands in a somewhat richer manner. Perception is fundamentally a mode of experience that is latent in all cognition, but is not reducible to the experience of cognition. Perception certainly hints at the more fruitful metaphysical structure that Benjamin calls the sphere of neutrality between subject and object. Perception also clearly has a historical dimension that Benjamin finds lacking in the cognitive, transcendental subject of the enlightenment, since perception only allows us to notice based on what we have perceived before. His brief reflections on experience even hint that perception establishes a continuum between different modes of experience, from normal to sane, from primitive to refined.

While Benjamin would continue to use the term perception quite often as a verb in his subsequent work, he no longer does so in a thematic way that would consider it as an absolute juncture of all experience. This notion of perception ties the early Benjamin to the phenomenological school and even to Hegel's Phenomenology, while his subsequent philosophy would seek a more original and less subject-oriented framework for experience. But in developing his own definition of perception, Benjamin articulates the way in which experience is inherently a linguistic process, one which finds seeks 'truth' in the legible temporal appearance of things. I argue that much of what he has to say on this level about perception continues forth in his thinking through a far more distinctive concept that he thematizes in his middle period: mimesis. The dependence of such perception on mimesis is clear in the following passage: "The gift we possess for seeing similarity is nothing but a feeble vestige of the once powerful compulsion to be similar and to behave mimetically." ${ }^{\text {"3 }}$ His definition of perception was fundamentally: the recognition of similarity in the realm of absolute surface appearance. Along the same line, he defines mimesis as the recognition and production of similarity in a free interplay between subject and object.

\subsection{Mimesis}

Although Benjamin writes of mimesis in a variety of contexts, he treats it most explicitly in an essay titled 'The Doctrine of the Similar' (and a revised version called 'On the Mimetic Capacity'). Mimesis is fundamentally the ability of life to produce similarities, such as the way an animal might mimic a plant for camouflage. While it is fundamental to life, it plays a special, decisive role in the development of the human species: he argues that all of our highest cognitive abilities emerge fundamentally from this primal capacity to make ourselves similar. Mimesis is the ability not only to notice patterns (perception), but to adapt our very being to these patterns in a creative manner. If we take cognition as one example of a higher capacity, then it is clear that our cognition rests on our capacity to note similarities and then produce something

42 'Notes on the Question of Perception', GS VI, 33.

43 'On the Mimetic Faculty', GS II 1, 210/SW 2.2, 691. 
new (a concept, a theory, an explanation) that resembles this pattern of similarities. Benjamin proposes that we could essentially understand the development of everything distinctively human, the emergence of 'higher' capacities, as both a withering and adaption of the mimetic behavior. Put another way, in humanity mimesis begins to have a history, begins to have linear or directional (geradlinig) development that leads to the creation of new capacities that pose both great opportunities and great dangers.

Benjamin's essay is thus interested not so much in the primal, original form of mimesis, but in what he calls the phylogenetic meaning of mimesis, the way in which mimesis has a history that shapes the development of human culture. ${ }^{44} \mathrm{At}$ first, it might seem as if Benjamin's essay is essentially a lament over the loss of mimesis in modern, rationalized culture. The recognition and production of similarities played a far more prevalent role in ancient modes of conduct, where occult relations of microcosm and macrocosm governed human thought. He speaks of the relative 'frailty' of the mimetic capacity in modern life. But the essay is not so much a lament over the loss of mimesis, as a diagnosis of the transformation within mimesis. Although he notes that the mimetic approach has "disappeared completely from certain domains of human life," such as the magical and animistic understanding of nature, he hypothesizes that "perhaps it has strayed and poured over into others." ${ }^{45} \mathrm{He}$ looks for a "uniform direction" in how mimesis has transformed and yet preserved itself in the behavior of the modern individual.

Benjamin proposes a solution: mimesis develops increasingly away from the recognition and production of sensible similarities to the recognition and production of non-sensible similarities, and it is our use of language that makes this evident. The mimetic capacity survives in our language, and language would not be possible without it. What does Benjamin mean by non-sensible similarity? He provides a few examples of non-sensible similarities: the relation of a word to a thing that it means; the relation between a written word and its spoken equivalent; the relation between words in different languages that mean the same thing. In what way does the word cat resemble an actual cat? In what way does the word livre in French resemble the word book? In what way does the sound that I make to say the word cat resemble the letters on the page that I read to mean the same thing? Benjamin poses this problem as follows: "If one orders the words of various languages around what they mean as if around their middle point, then we would need to investigate how it is that all of these words, which often bear no resemblance with one another, are nevertheless all similar to that which they mean in their center." ${ }^{46}$ It might seem if there is no connection whatsoever, except for an arbitrary agreement between people to treat one thing as relating to another, or a complex history of such agreements. But Benjamin argues that such conventional language would not be possible without some deeper ability for producing similarity.

The resemblance is not given to the senses, but nor is the relation between word and thing completely arbitrary. We do not simply choose a word to signify a thing through an arbitrary act of substitution, but we produce this similarity by making our experience converge. Each language is an archive of mimetic acts, and whenever we name, translate or read, we produce or reproduce a similarity that is not sensible. Of course there is a conventional and seemingly arbitrary aspect of language, where I use a word to mean something because it has been used this way by others, but it would be impossible to create language in the first place without a mimetic act, without the production of a non-sensible resemblance, just as it would be impossible to learn conventional language or even to use it to express anything creatively without a mimetic act. There is a passive and conventional use of language, in which the mimetic act is hidden or unimportant; but Benjamin argues that fundamentally, language would not be possible without a magical element. This magic of language is the capacity of human thought and experience to bring into being a bond between things that does not have any tangible objectivity. "Language now makes up the medium in which things encounter and enter into relationship with each other, no longer directly in the spirit of the shaman or priest, but now in their distilled essences, their fleeting substances and aromas." ${ }^{\$ 7}$

44 Michael Taussig offers an anthropological account of mimesis that derives from Benjamin, defining mimesis as follows: "The nature that culture uses to create a second nature, the faculty to copy, imitate, make models, explore difference, yield into and become Other". Taussig, Mimesis and Alterity: A Particular History of the Senses, xiii.

45 'Doctrine of the Similar', SW 2.2, 695/GS II 1, 205.

46 Ibid., 207.

47 Ibid., 209. 
There is undoubtedly something confusing and incomplete about Benjamin's theory of non-sensible similarity. How can we make sense of a similarity that is not literal or objective, but a product of the ephemeral, spiritual connection between things? How are these non-sensible similarities more than arbitrary impressions? Thankfully, Benjamin writes another essay that dwells on just this problem in a manner that at least articulates the riddle, 'Analogy and Relation.' An analogy involves an external act of comparison between two objects, a search for their defining similarity, while Verwandschaft (relatedness, in the sense of familial relation) involves a direct experience of the internal, historical dynamic by which two things are intertwined. We do not know the relation of the father to the child through their common features, nor even through their causal connection. In comparison to the classifying procedure of forming definitions through analogies, Benjamin writes: "The essence of relatedness is enigmatic... One needs a particularly peaceful and undisturbed glance in order to recognize it." ${ }^{48}$ Such a gaze must go beyond the surface and look for signs of the internal dynamic by which things engender one another. He considers Nietzsche's genealogical investigation of moral values as a fruitful example of such a glance that is 'soft' and yet probing enough to discover a parental or familial relation between moral imperatives that seem utterly opposed on the surface. In one of the most startlingly original essays of Benjamin's early period, he examines capitalism as a parasite of Christianity that threatens to destroy it. Relatedness is not a matter of comparing the external features of objects to reach an overarching generality, but a matter of tracing the common spark that generates differences out of a dynamic common root. Verwandschaft seems connected to Verwandlung-metamorphosis. A knowledge of relatedness implies an understanding of transformation, as well as what remains latently similar underneath the transformation. This relatedness is enigmatic from the perspective of classificatory knowledge and it hides from the kind of investigation that seeks causal determination of one thing through another, but in Benjamin's essay, he seems focused on the idea that there is an experience of relatedness, a certain kind of sensitivity for it, that comes from the ability to present phenomena in the proper constellation to one another. Benjamin's later notion of non-sensible similarity seems to rest on this interest in gaining an experience of the inner connection between things that transcends their superficial or external resemblance.

The whole phenomenon of mimesis has a crucial connection to the way that similarities appear in time: "Their perception (i.e. of similarities) is bound up with a flashing forth (Aufblitzen)." ${ }^{49}$ There is a momentary occasion in which one thing appears in a certain constellation to others, and we have to seize this moment in order to produce a similarity. There is a perspectival and historical genealogy to mimetic acts. The set of similarities is not objectively given and fixed, but a matter of constantly looking at the configuration of things in their continuity and alternation. This is true of the kinds of non-sensible similarities that are archived in language. The words that we get to use are an archive of the historical experience of a culture. The etymology of a word tells us of the connection between one culture and another. The vocabulary of a language tells us what this language has experienced, which experiences have become sanctioned events within a culture and remained so over time. At the border of established language, we are encountering new experiences, such as the relation to another language, or experiences brought about by a new economic and technological configuration of events. New words are invented, borrowed from other languages or coined to mark these new experiences, and poets and philosophers deliberately use established words in a challenging or ambiguous way in order to suggest constellations that are not ordinary or sanctioned. Whether these new constellations have objectivity or not depends not so much an on the community's acceptance, but more on the quality of 'flashing forth,' the momentary appearance of a constellation between different experiences. The non-sensible similarity between things is not simply an arbitrary connection between them, but it is a frail connection because it rests on the capacity to see things in their historical constellation. This means that memory is just as important as openness to new configurations: openness to new and temporary configurations of allows constellations to acquire objectivity, while memory allows past, fleeting constellations to maintain their objectivity across historical time.

48 'Analogy and Relation', GS VI, 43-44.

49 'Doctrine of the Similar', SW 2.2, 695/GS II 1, 206. 
Benjamin's theory of mimesis contains his earlier notion of perception, but it also goes beyond it in important ways. Throughout his essay 'The Doctrine of the Similar' he uses the term Wahrnehmung: the mimetic capacity 'perceives' non-sensible similarities. Perception, as we saw, is fundamentally the capacity to recognize things according to their experienced similarity, a vision not for things in their immediacy, but for their meaning within a continuum of lived significance, a point Benjamin makes clear in his thesis that 'Perception is reading'. Perception thus already included a linguistic component. But Benjamin's theory of mimesis adds a few crucial elements to his earlier notion of perception: mimesis is a perception that is bound to a momentary, historical occurrence of a configuration. It is a reading that is guided by the unfolding of temporary events. Additionally, the accent is not merely on the recognition of similarities, but on the production of novel similarities that are based in experiential connections. A set of questions emerge from Benjamin's doctrine of mimesis: Are these similarities given or are they made by the subject? Are they objective or are they arbitrary? If they are fleeting, then why should they be seized on and carried forward across time? Benjamin's essay implies that they are objective in the sense that they involve receptivity from the subject, but mimesis goes beyond perception in the sense that it involves making the self similar to the pattern that is recognized. It is both the recognition of a set of non-sensible similarities as well as the assimilation of oneself to these similarities. This is the sense in which it is productive and creative.

\subsection{Language}

Benjamin's theory of mimesis culminates in positing language as the highest and most historically informed mode of mimesis, just as his theory of perception culminates in the notion that 'perception is reading.' This suggests that language plays a central role in his exploration of experience. Indeed, in one of his early texts on perception he posits that 'Absolute experience is language. ${ }^{50}$ What does Benjamin mean by positing this definitional identity between experience and language ${ }^{51}$ And what notion of language is operative in his early thought? Benjamin is one of several thinkers from the early $20^{\text {th }}$ century who instigate a linguistic turn in philosophy. But when Benjamin writes of language, he challenges our contemporary philosophical understanding to the utmost, because he does not merely mean the language of words and sentences, of assertions and propositions, nor even the language of ordinary speech acts. All of these represent only one aspect or kind of language, 'the language of human beings,' not language as such. When Benjamin thinks of language in general, he has in mind that even things that do not speak in words have a different kind of language: the language of dance and music, the language of painting and architecture, as well as the language of natural things.

When Benjamin writes in 1917, at the culmination of his essay on perception, that 'Absolute experience is language,' it is crucial that we do not insert our own, modern and arbitrary understanding of language into this space. By this point, Benjamin has already undertaken a deep investigation of the concept of language and arrived at what he calls a 'purified notion of language' and a refutation of what he calls the 'bourgeois notion of language,' a notion which he says 'proves its untenability to a greater degree every day.' I am speaking here of Benjamin's 1916 essay 'On human language and language as such.' What is this purified notion of language? Language is fundamentally an expression of the spiritual or intellectual (geistig) content of things. There is a language of things, a mute language, that gets translated into words through an act of recognition. All true understanding is fundamentally a recognition of the spiritual nature of a thing that allows us to translate this thing's mute language into an articulate language. If things did not communicate something to us, then we would not recognize them. He dismisses what he calls the 'bourgeois' view that

50 ‘On Perception', SW 1, 96/GS VI, 38.

51 As Michael Bröcker argues, the language essay is one of the most complete attempts that Benjamin made to unfold the tasks laid out in the 'Program of the Coming Philosophy.' In particular it responds to the idea of establishing a closer connection between knowledge and language as a correction of the enlightenment view of experience. See Bröcker, Die Grundlosigkeit der Wahrheit: Zum Verhältnis von Sprache, Geschichte und Theologie bei Walter Benjamin. See also Hansen, 'Language and Mimesis in Walter Benjamin's Work'. Hansen's study highlights the continuity of Benjamin's thinking on language, even in his later work, by carefully explicating a series of related terms: experience, similarity, mimesis, translation. 
language is a set of agreed upon signs used to communicate our mental contents to each other. While it is possible that we can use words in such an arbitrary way, to express our thoughts according to an accepted practice, this is by no means the only or proper way of construing the true relation between words and things, because it assumes a human experience of the world that is wholly external and instrumental to these things.

Benjamin uses an analogy from the arts to explain the origin of human language in the language of things: poetry uses words to make art, just as music uses tones, sculpture uses material and painting uses colors. Each of these media, words, tones, material and color also exist outside of art. Material communicates with other material in nature, color communicates with color in our perceptions, and the artistic use of these media derives from such natural communication. When we speak of anything using words, we translate the language of things into the language of words, one medium of expression into another. The language of words is the highest mode of language in terms of its intensity and universality, but it is responsive to a moment of recognition that is already tacitly linguistic. A true recognition of things includes not only what they mutely communicate to us, but also what they withhold from us. Words are thus just as much an expression of the spiritual content of things as they are also symbols of the aspect of things that withdraws from communication. "Language is not just the communication of what can be communicated, but also a symbol of what cannot be communicated." 52

It would be easy to characterize this early essay on language as an expression of a mystical and religious belief, without taking it seriously as shaping Benjamin's philosophical program. Yet its fundamental insight into the nature of language plays a crucial role in his philosophy of experience, as well as his later notion of mimesis. When Benjamin argues a year later that 'Absolute experience is language', he expands in the following manner: "Language (must be) understood, however as a systematic, symbolic concept. It is articulated in types of language, one of which perception." ${ }^{33}$ Benjamin's theory of language is fundamentally a theory of the relation between a multitude of languages, which is to say, it is a theory that elevates translation into the foremost metaphysical problem. And here, Benjamin tells us that perception is to be understood within this greater continuum of how languages relate and cohere. A more conventional metaphysics might say that we translate experience into language, that we take ideas that are sensed, perceived or felt and bring them into words. But for Benjamin, perception is a form of language that is not, however, equivalent to the language of words. Perception is a primary act of mimesis, a translation of the spiritual essence of objects into a language. It is a middle term between the two terms of his early language essay: the language of things and the language of words. Absolute experience is language in the sense that it is the approach to things that finds a continuum between various languages and looks to translate them.

\subsection{Romantic Observation}

It is impossible to discuss Benjamin's philosophy of experience without briefly mentioning the single most fruitful historical model that Benjamin found for such a philosophy of experience: his interpretation of early German Romanticism. While his dissertation on the Romantic theory of criticism influenced and has revolutionized the scholarship of German Romanticism and remains a valuable secondary source, it is hard to account for the role this work plays in the development of Benjamin's thought. ${ }^{54}$ In the key late fragment defining the notion of experience, he off handedly mentions the Romantic theory as possessing a crucial significance for his own thought. It begins "Lived similarities are experience," and then continues "The identity of experience and observation is to be proven. See the notion of 'romantic observation' in my dissertation. Observation resting on immersion." ${ }^{55}$ This fragment implies that Benjamin considers the doctrine of similarity, treated above, to be fundamentally related to the core metaphysical insight of his

52 'On Language in general and the language of humans', SW 1, 74/GS II 1, 156.

53 'On Perception', SW 1, 96/GS VI, 38.

54 See Hanssen and Andrew Benjamin, eds. Benjamin and Romanticism. The work offers a variety of perspectives on how Benjamin's later work relates to his dissertation.

55 'On Experience', SW 2.2, 553/GS VI, 89. 
dissertation on the Romantics. The core insight of the dissertation is this: according to the Romantics, we can only have knowledge within a medium of reflection. We can only know objects by knowing them as subjects, as capable of their own subjective reflection. This means that immersion in a medium of experience, rather than judging of objects according to values or concepts, is the model for an authentic criticism.

In Benjamin's rendering of the Romantics, to gain true knowledge means fundamentally to 'observe' an object. This model of observation applies just as much to experiments on natural processes as it does to the critique of art works. To observe an object means both to put the object in a 'natural' continuum of the objects to which it is related, as well as to treat this object as a being that is capable of its own reflection, its own subjective self-awareness. To observe means to take the reflection that is already embodied in the object and to give expression to this internal dynamic. This mode of observation takes the 'mere' object and makes it into subject, but it also dissolves its independence and treats it as a moment of reflection within a continuum of forms. Benjamin posits that this Romantic doctrine of observation is most fruitful in relation to artworks, since we recognize artworks literally as both objects of experience and products of subjective creation, but he also interprets this doctrine observation as an overall theory of object knowledge. How does this provide a solution to the problem of experience discussed above?

A few years before his dissertation, Benjamin's early 'Program' posits a need to move beyond what it calls the 'fruitless metaphysics of subject and object,' which it identifies with Kant and the enlightenment. He regards the enlightenment's notion of experience as 'fruitless' because of the way that the subject is always relating to something outside of itself that it construes as unavailable and passive, but also because it takes the subject-object relationship out of the context of its true medium, history. Benjamin seems to have briefly considered both Kant's writings on history and Hegel's dialectical philosophy as potentially offering a more fruitful metaphysical conception of experience. He rejects both of these models of experience for a variety of reasons, but none is more explicit than his rejection of their common notion of historical progress. His study of the Romantics provides him with a more fruitful alternative that would shape his thinking in an original direction. They provide a more 'fruitful' metaphysics, in the sense that they regard the object as only knowable within a medium of reflection. This notion posits an alternative to two assumptions that Benjamin had found wanting in the Enlightenment: the notion of the object as passive and the notion of the framework or medium of experience as ahistorical. With their notion of the medium of reflection, they interpret the object as only knowable through its internal reflection, and they see the overall framework of experience as a historical process of development, but not progress. With his reading of the German Romantics, as much as it might be framed through the problems of his early philosophy, ${ }^{56}$ Benjamin posits a model for thinking of the subject-object relationship as a medium in such a way as to make good on some of the key demands from his 'Program.'

\subsection{Memory}

Up to this point, I have explained Benjamin's notion of absolute experience through a constellation of terms that he employs at different phases: perception, mimesis, language and observation as immersion. At the heart of each of these figures lies another crucial aspect: memory. Perception is not the immediate absorption of information, but the recognition of similarities based on experience. Observation is the immersion of

\footnotetext{
56 An influential reading of Benjamin's study of the Romantics argues that he distorts their philosophies by assimilating them to his own early 'language mysticism'. Menninghaus, 'Walter Benjamin's Exposition of the Romantic Theory of Reflection' in Walter Benjamin and Romanticism. In general, his reading of Romantics has been influential but is out of step with more epistemic readings that have prevailed recently. It is not here possible to deal with the complexities of Benjamin's reading of the Romantics, but in the context of the present study it seems important to point out that the notion of 'language mysticism' provides a gross oversimplification of the intellectual motivations that Benjamin had for finding sympathetic themes in early German Romanticism. Indeed, more could be gleaned of Benjamin's own relation to the Romantics by reading this study in relation to his early Program than by placing it in the context of the language essay. Like the early German Romantics, Benjamin was intensely immersed in Kant's theory of object knowledge and resolving certain difficulties having to do with the 'thing in itself'.
} 
one's attention in the object until it turns into a medium of reflection, something that offers an infinite and inexhaustible pattern of reflection. Even language is, in Benjamin's view, an archive of lived similarities. Each of these notions points towards memory as both the basis of true experience, as well as the true goal or measure of experience. Experience is both a process of on-going openness ('to have an experience'), as well as a participle ('she has experience at this'). It seems clear that we cannot gain experience if we do not have memory. But in what sense is memory not merely an element required for experience, but a purpose that illuminates the intrinsic meaning of experience?

In those writings where he thematizes memory, Benjamin challenges us to think of it in a new way: not as a means for recalling the past, but rather as a medium in which the past continues to exist and reconfigure itself in new constellations. There are two metaphors that Benjamin uses to challenge a straightforward view of memory: the metaphor of excavation, and the metaphor of Penelope's work of weaving.

Benjamin uses the metaphor of an archaeological excavation to convey the authentic capacity of memory: memory is to be understood not simply as the pile of objects that one has excavated, but far more as the layers of earth in which they have been found. "Memory (Gedächtnis) is not an instrument for the discovery of the past, but rather the medium. It is the medium of what has been lived through (des Erlebten), just as the soil is the medium in which old cities are buried. ${ }^{{ }^{77}} \mathrm{An}$ archaeologist who simply digs up the earth to get at artifacts without carefully noting the layers of earth from which they have been excavated would be throwing away the true subject of enquiry. Following this metaphor, Benjamin argues that true memory requires us to recall an event not just in the context of its own layer, but also in the context of all of the layers that we had to dig through in order to get to it. Memory is not a storage container that keeps things from the past in the present, but an understanding of the way that things become past, the way that events gain a different meaning now than they had when they occurred. Authentic memory even requires forgetting: we cannot properly remember something unless it has been forgotten, and memory does not bring it out of forgetting, but allows us to make the forces of forgetting into a layer that enriches our understanding our awareness of the past. As Stéphane Symons writes: “In Benjamin's view, recollection does not represent the sheer absence of forgetfulness, but the fact that forgetfulness has been made operative." 58

It is most of all in his encounter with Proust that Benjamin discovers how fruitful a theme memory can become in grasping the nature of experience. When Proust writes about his own life, he engages in a kind of literary experiment on his own faculty of memory, and in Benjamin's rendering, this experiment has results that are of the utmost significance for his own first philosophy. At each point, Benjamin defines experiences through 'lived similarities'. Proust's experiment is to weave a text that approaches lived similarities through a pattern of involuntary memory. "Proust's involuntary memory bears a closer resemblance to forgetting than what we would normally call remembering. ${ }^{59}$ Remembering in this way bears such a resemblance to forgetting because it involves unweaving what memory has woven in order to reweave it according to a different method. Benjamin thus uses the image of Penelope's weaving and unweaving as a metaphor for Proust's pattern of literary weaving. Proust's writing has to unweave because it does not seek to reconstruct a causal account of events over time, but rather it seeks a delicate web of resemblances between the impressions of events. As these impressions enter into new configurations in the act of memory, resemblances emerge that could not have been experienced at the time, and sometimes these resemblances show us the true significance of an event. It is not the linear or causal connection that allows us to know the true meaning of an experience, but rather an observation of the remembered thing according to its recollected similarity. His writing attends to the impression that an event has in its relation to a discrete series of similar events. It is not a matter of going back and discovering what really happened by telling a coherent, logical story, but a matter of seeing how the event holds together with others in a delicate web of resemblances that have remembered meaning. Memory is thus not a replication of events that have been lived through, but a production of a new layer of meaning that draws from life but attains a truth content that could not be achieved in living through the present.

57 'Excavation and Memory', SW 2.2, 576/GS IV, 400.

58 Symons, More Than Life: Georg Simmel and Walter Benjamin on Art, 156.

59 'On the Image of Proust', GS II 1, 311. 
But how is it possible that this non-linear, non-causal set of remembered similarities attains a truth content that is distinctive to memory? The remembered event is not a pale copy of an experience, but the true experience, because it has been taken out of a context that reduced it to something lacking in intrinsic value, and reintroduces it into a context where it has experienced significance. Benjamin writes: "For an event that has been lived through (erlebt) is finite, at least in the sense that it is closed in a particular area of lived experience, yet a remembered one is limitless, because it is merely a key to everything that comes before it and after it." 60 There is a reductive but also ordinary mode of experience that Benjamin here refers to as Erlebnis in which each event is processed by being reduced to a uniform stream of events where one leads to the next in a chain of substitution. But even though this mode of experience might be the key to cognizing events in a predictable and uniform way, it is also a reductive mode of experience, because it does not allow anything to enter into its own relationship with anything else. True experience would liberate things from this kind of functionality by allowing them to have a significance that is unlimited and yet coherent in a constellation of reflective relationships. Ultimately, Proust's literary experiment is motivated by a search for the kind of experience that would fulfill human life in the act of reflection. Benjamin reads Proust as a writer who is seeking a kind of happiness through the act of writing. This happiness is only to be found in the act of writing, precisely because it is not found in life, unless this life is worked through in a particular way. He writes of Proust's search for happiness as "homesickness for a world that is distorted in a state of similarities, a world in which the truly surrealistic face of existence breaks through." ${ }^{61}$ If Benjamin's entire philosophical project is a search for a new model of experience, and if this experience is defined fundamentally as a fruitful capacity for 'lived similarity', then this notion of memory is the highest potency of experience.

Proust's notion of involuntary memory offers Benjamin an intensification of all of the themes of his earlier philosophy of experience: it is the perception of perception. Perception is the recognition of things according to a pattern of lived similarities. Memory is the mode of experience in which such acts of perception become aware of their own significance outside of a reductive chain of causality. Memory is perception for the sake of perception, as well as perception of the inner logic by which lived similarities generate one another by reflecting on one another. Such experience to the second degree is only possible on the basis of past life, but it is also only possible at a reflective distance from life. At the same time, memory is crucial to understanding Benjamin's philosophy of language, because it is the mode of experience that liberates language and purifies it from what Benjamin had called its 'bourgeois' form. He considers language as an archive of past mimetic acts, and as a 'medium' in which the purified spiritual essence of things co-mingle. In accord with this purified notion of language, it is not the use of language to communicate information, but rather the use of language to construct an account of life according to similarity, a life of the second order, that reveals the magic of language.

Benjamin's philosophy of memory gains a special significance in his late work, The Arcades Project, not only as a process of personal fulfillment through self-reflection, as it may seem in Proust, but as a general methodological principle for how to gain an experiential relation to history. "Just as Proust begins the story of his life with an awakening, so must every presentation of history begin with an awakening; in fact, it should treat of nothing else." 62

\section{Conclusion}

Benjamin fills in his program of seeking a new model of experience by developing an interlocking series of notions of experience: perception, language, mimesis, observation and memory. Each of these rests on the others for explanation, and entails an unaccustomed way of looking at experience. We might be able to envision what it would be like to have some of these experiences, but to what extent do these models of experience represent a first philosophy?

60 Ibid., 312.

61 Ibid., 314.

62 Benjamin, The Arcades Project, 464. 
It is hard to see the philosophical import of this notion of experience without posing the question of truth. Experience might appear, when taken in isolation, as an infinite, open-ended process, with no goal, no ideal form, and no standard of differentiation. Yet Benjamin's early philosophy of experience departs from the demand that the continuum of experience be differentiated in terms of its value. The first section briefly cited, among others, the following demand in Benjamin's early 'Program for the Coming Philosophy': "Error can no longer be explained in terms of erring, truth no longer in terms of the correct understanding." Each of the models of experience that I treated here has to be understood as, in some respect, related to the notion of truth and error, perhaps none more so than the final one treated here, memory, where we saw that the project of remembering life is not so much a matter of accurately reproducing biographical details, but giving them fulfillment through a kind of transformational self-understanding that does not so much negate forgetfulness as enter into it to gain access to its genesis and meaning. And yet Benjamin's conception of truth is both highly unconventional, at least when placed against the backdrop of modern epistemology, and it is thematized in a many sided way throughout a variety of texts, such that giving definition to it as a counter-pole to his philosophy of experience would require another article. ${ }^{64}$ What makes his notion of truth unconventional, yet influential, is that he does not grasp truth as a property of correct acts of knowledge, but as an elusive, temporal relationship between things or 'circumstances.' The basis of this study on the concept of truth in Benjamin would be both the 'Epistemo-critical Prologue' and Convolute $\mathrm{N}$ of The Arcades Project. It would examine the notion that truth is only present as intentionless state of being, which gets 'displayed' through an intuitive constellation of historical circumstances. Such a study is not possible here, as it would involve the placing together of a series of theses no shorter than the one presented her to give definition to the notion of experience. Yet this problem must at least be mentioned here in order to avoid the appearance that Benjamin's philosophy of experience simply floats in a kind of nihilistic void, devoid of any ideal that would tie it to the pursuit of truth through reflection.

\section{References}

Adorno, Theodor W. Negative Dialectics. Transl. EB Ashton. New York: Continuum, 2007.

Adorno, Theodor W. 'Einleitung zu Benjamins Schriften’ in: Noten zur Literatur. Frankfurt: Surhkamp, 1974, 570-582.

Benjamin, Walter. Gesammelte Schriften. Frankfurt am Main: Suhrkamp, 1977.

Benjamin, Walter. The Arcades Project. Cambridge: Harvard University Press, 1999.

Benjamin, Walter. Walter Benjamin Selected Works, ed. Howard Eiland and Michael Jennings. Cambridge: Harvard University Press, 1996-2004.

Bröcker, Michael. Die Grundlosigkeit der Wahrheit: Zum Verhältnis von Sprache, Geschichte und Theologie bei Walter

Benjamin. Würzburg: Könighausen, 1993.

Caygill, Howard. Walter Benjamin: The Colour of Experience. New York: Routledge, 1998.

Eiland, Howard and Jennings, Michael. Walter Benjamin: A Critical Life. Cambridge: Harvard University Press, 2016.

Hanssen, Beatrice. 'Language and mimesis in Walter Benjamin's work' in The Cambridge Companion to Walter Benjamin.

Cambridge: Cambridge University Press, 2004, 54-72.

Hanssen, Beatrice and Andrew Benjamin, eds. Benjamin and Romanticism. London: Continuum, 2002.

Menninghaus, Winfried. 'Walter Benjamin's Exposition of the Romantic Theory of Reflection' in Walter Benjamin and

Romanticism, ed. Beatrice Hansen and Andrew Benjamin. London: Continuum, 2002, 9-18.

Ponzi, Mauro. Nietzsche's Nihilism in Walter Benjamin. New York: Palgrave, 2017.

Symons, Stéphane. More Than Life: Georg Simmel and Walter Benjamin on Art. Evanston: Northwestern University Press.

Tagliacozzo, Tamara. Experience and Infinite Task: Knowledge, Language, and Messianism in the Philosophy of Walter

Benjamin. Lanham: Rowman and Littlefield International, 2018.

Taussig, Michael. Mimesis and Alterity: A Particular History of the Senses. New York: Routledge, 1993.

Wolin, Richard. Walter Benjamin: An Aesthetics of Redemption. Berkeley: UC Press, 1994.

63 'Program', SW 1, 107/GS II 1, 167.

64 Such a study would emphasize the following theses: 1) The truth is not a property of acts of knowledge. We cannot know the truth. 2) Truth is a moral/political problem: it stands in opposition not just to lies, but to 'objective mendacity'. 3) The artwork is an illustration of truth; but only when understood in its criticizeability/translateability. 4) Truth is a property of 'circumstances'-the relation of things to a perfect state. 5) Truth is an intentionless state of being. 6) The truth is not timeless: it is temporal, historical. 